\title{
Heading for trouble: is dementia a game changer for football?
}

\author{
A Rutherford, ${ }^{1}$ William Stewart, ${ }^{2}$ Davide Bruno ${ }^{3}$
}

\section{INTRODUCTION}

After fevered media coverage of a possible link between football (soccer) heading and long-term damage to the brain, 2016 saw the Professional Footballers' Association call for a review of the game to decide whether to follow the lead of the United States Soccer and ban heading for younger players. Given these concerns, and the fact the relevant Rules of Football were conceived over 100 years ago, is it time for major rule changes? Is there evidence that football increases risk of neurodegenerative disease (eg, dementia) and heading is to blame?

\section{(NO) DATA ON DEMENTIA RISK IN FOOTBALL}

Remarkably, despite phenomenal football participation rates globally and over a century of participation, there is little evidence regarding football's impact on brain health, and dementia in particular. Football is a contact sport and concussive head injuries do occur, but multiple reviews of the available research literature have drawn the same conclusions: football concussion outcomes are consistent with the general concussion literature, with weak to non-existent evidence for a link between football play and long-term neurological or cognitive deficits. $^{1-3}$ However, a common feature of most football research so far has been the recruitment and study of young active footballers, arguably too young to show late cognitive effects.

This limitation was addressed to an extent by a self-assessment study (92 respondents) conducted with former UK professional footballers aged 55 and over. ${ }^{4}$ The proportion of respondents screened and reporting positive for possible mild cognitive impairment, and possible dementia, was consistent with general population expectations, but with such a

\footnotetext{
'School of Psychology, Keele University, Keele, UK ${ }^{2}$ Queen Elizabeth University Hospital and Institute of Neuroscience and Psychology, University of Glasgow, Glasgow, UK

${ }^{3}$ School of Natural Sciences and Psychology, Liverpool John Moores University, Liverpool, UK

Correspondence to Dr A Rutherford, School of Psychology, Faculty of Natural Sciences, Keele University, Keele, Staffordshire ST5 5BG, UK; a.rutherford@keele.ac.uk
}

limited sample, no control group and a study methodology open to case selection bias, beyond 'more work is required', no meaningful conclusion can be drawn.

\section{(CONFOUNDING) DATA ON THE CONSEQUENCES OF FOOTBALL HEADING}

Research on the immediate effects of football heading alone is sparse, with one recent study reporting evidence of shortlived impairment in cognitive and electrophysiological assessments after a single session of 20 headers by young footballers. ${ }^{5}$ However, no controls were included and effects normalised within 24 hours. So, while intriguing, the data provide no insight into any long-term consequences of heading.

Regarding late consequences of heading, data are mixed and limited. No correlation between heading frequency and neurocognitive test performance is reported in a majority of studies, while the remainder report only minor and sometimes questionable influence of heading, ${ }^{12}$ with surprisingly few studies applying the recommended control for the confounding effects of a greater number of head injuries sustained by those who head more frequently. ${ }^{2}$ Intriguingly, an inverse correlation between heading exposure and MRI measures of cortical thickness in former professional footballers has been reported and associated with cognitive performance, ${ }^{6}$ but again data are mixed across the few imaging studies to date, with no direct correlation reported in others.

\section{DO FOOTBALLERS' BRAINS LOOK LIKE BOXERS'?}

There is increased recognition of chronic traumatic encephalopathy (CTE) in non-boxer athletes in a growing list of sports, ${ }^{7}$ including small numbers of cases in former footballers. ${ }^{8}$ While these reports capture headlines, as observational studies on serendipitous brain donations (ie, without appropriate sampling of sport population), they provide no insight into the risk of CTE in a sport, let alone enlightenment on causality. ${ }^{2}$ Notably, there are no validated operational clinical criteria for CTE, which still requires autopsy confirmation. ${ }^{7}$ Consequently, awareness remains low, with exceptionally few suspected cases undergoing autopsy evaluation. Nevertheless, it remains premature, if not inappropriate, to equate the neuropathological consequences of football to a lifetime of boxing based on such isolated cases.

\section{WORK TO DO BEFORE RULE CHANGE IS INFORMED}

Current evidence suggests the concerns and anxieties expressed in many quarters of the media around football participation, specifically the act of heading the ball increasing dementia risk, are unsubstantiated. Nevertheless, growing public anxiety around the consequences of exposure to brain injury in sport, partly fuelled by increasing recognition of CTE in former athletes, must be acknowledged.

However, in reality there are remarkably few robust and enlightening studies on the long-term neuropsychological health of former footballers, or on the lasting consequences of football heading. Not only is most research to date beset by methodological deficiencies, ${ }^{1}{ }^{2}$ those studies exhibiting methodological deficiencies are most likely to identify neuropsychological impairment. $^{2}$

While current evidence does not demand rule change, neither does it provide football with a clean bill of health. Instead, to inform discussions and assuage anxieties, there is a pressing need for appropriately designed and powered research studies to address questions over dementia risk in former footballers and any long-term consequences of heading. Until then, recommendations on heading in association football will be driven by opinion, not by scientific evidence. Therefore, the recent EUFA and Football Association calls for research to fill these knowledge gaps are welcomed and demonstrate a commitment to address these serious issues.

Contributors AR with assistance from DB wrote the first draft of the manuscript. WS substantially revised this first draft for publication as an editorial. This was tweaked by AR, who then submitted the manuscript's final draft. The revisions requested were addressed by AR's discussion with WS and DB.

Competing interests None declared.

Provenance and peer review Not commissioned; externally peer reviewed.

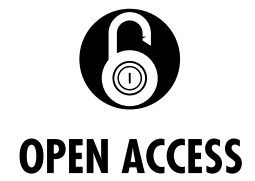

Open access This is an open access article distributed in accordance with the Creative Commons Attribution Non Commercial (CC BY-NC 4.0) license, which permits 


\section{Editorial}

others to distribute, remix, adapt, build upon this work non-commercially, and license their derivative works on different terms, provided the original work is properly cited and the use is non-commercial. See: http:// creativecommons.org/licenses/by-nc/4.0/

(c) Article author(s) (or their employer(s) unless otherwise stated in the text of the article) 2019. All rights reserved. No commercial use is permitted unless otherwise expressly granted.

D) Check for updates

To cite Rutherford A, Stewart W, Bruno D. Br J Sports Med 2019;53:321-322.

Accepted 5 July 2017

Published Online First 20 July 2017

Br J Sports Med 2019;53:321-322. doi:10.1136/bjsports-2017-097627

\section{REFERENCES}

1 Rutherford A, Stephens R, Potter D. The neuropsychology of heading and head trauma in Association Football (soccer): a review. Neuropsychol Rev 2003;13:153-79.

2 Tarnutzer AA, Straumann D, Brugger P, et al. Persistent effects of playing football and associated (subconcussive) head trauma on brain structure and function: a systematic review of the literature. $\mathrm{Br}$ Sports Med 2016:bjsports-2016-096593 (Epub ahead of print).

3 McCrory P, Meeuwisse W, Dvořák J, et al. Consensus statement on concussion in sport- the 5thinternationa conference on concussion in sport held in Berlin, October 2016. British Journal of Sports Medicine 2017;51:838-47.
4 Vann Jones SA, Breakey RW, Evans PJ. Heading in football, long-term cognitive decline and dementia: evidence from screening retired professional footballers. Br J Sports Med 2014;48:159-61.

5 Di Virgilio TG, Hunter A, Wilson L, et al. Evidence for acute electrophysiological and cognitive changes following routine Soccer heading. EBioMedicine 2016;13:66-71.

6 Koerte IK, Mayinger M, Muehlmann M, et al. Cortical thinning in former professional soccer players. Brain Imaging Behav 2016;10:792-8.

7 Smith DH, Johnson VE, Stewart W. Chronic neuropathologies of single and repetitive TBI: substrates of dementia? Nat Rev Neurol 2013;9:211-21.

8 Ling H, Morris HR, Neal JW, et al. Mixed pathologies including chronic traumatic encephalopathy account for dementia in retired association football (soccer) players. Acta Neuropathol 2017;133:337-52. 